\title{
A cientificidade marxiana nos Prologomena de Lukács*
}

\section{Antônio José Lopes Alves**}

\begin{abstract}
Resumo: No presente artigo, são explicitados e analisados os principais elementos da compreensão lukácsiana acerca do padrão de cientificidade que caracteriza $\circ$ pensamento marxiano, conforme consignado em sua última obra dedicada à questão da ontologia: Prolegômenos para uma Ontologia do Ser Social. Expondo e elucidando os pontos mais decisivos deste tema no "último" Lukács, procede-se igualmente um cotejamento à forma pela qual este problema foi enfrentado pelo autor em Para uma Ontologia do Ser Social. O que é visível na análise da cientificidade marxiana procedida por Lukács é o reconhecimento de uma conexão essencial entre a constituição da coisa como coisa e a formulação do conhecimento teórico acerca dela. Nesse, como em quase todos os momentos da fase madura de seu pensamento, percebe-se que Lukács encarava como uma das tarefas mais importantes para a reconstrução de uma perspectiva teórica autenticamente revolucionária a crítica rigorosa das versões mecanicistas do pensamento marxiano. Uma vez que as categorias científicas portam virtualmente esse caráter de expressões da concretude do ser, o conhecimento em Marx, segundo Lukács, tem como uma das suas determinações o fato de ser irremediavelmente post festum.
\end{abstract}

Palavras-chave: Lukács; Marx; cientificidade; Prolegômenos; ontologia.

\begin{abstract}
In the present article, the main elements of lukacsian's understanding about the pattern of scientificity that characterizes Marxian thought are explained and analyzed, as set out in his last work dedicated to the issue of ontology: Prolegomena for an Ontology of Social Being. Exposing and elucidating the most decisive points of this theme in the "last" Lukács, there is also a comparison to the way in which this problem was faced by the author in The Ontology of Social Being. What is visible in the analysis of Marxian scientificity carried out by Lukács is the recognition of an essential connection between the constitution of the thing as a thing and the formulation of theoretical knowledge about it. In this regard to almost every moment of the mature phase of his thought, it is perceived that Lukács saw as one of the most important tasks for the reconstruction of an authentically revolutionary theoretical perspective the rigorous criticism of the mechanistic versions of Marxian thought. Since scientific categories virtually have this character of expressions of the concreteness of being, knowledge in Marx, according to Lukács, has as one of its determinations the fact of being necessarily post festum.
\end{abstract}

Keywords: Lukács; Marx; scientificity; Prolegomena; ontology.

Ao contrário do que se observa em Para uma Ontologia do Ser Social, nos Prolegômenos a uma Ontologia Enfim Tornada Possível, não há uma divisão de temas

\footnotetext{
"Reedição, com modificações do artigo originariamente publicado em: VAISMAN, Ester; VEDDA, Miguel (Orgs.). Arte, filosofia e sociedade. São Paulo: Intermeios, 2014.

Professor titular da UFMG. Doutor (UNICAMP) e Mestre (UFMG) em Filosofia. Docente no Colégio Técnico (UFMG), no Programa de Pós-Graduação em Educação: conhecimento e inclusão social e no Mestrado Profissional em Educação e Docência, ambos também da UFMG. Membro do Grupo de Pesquisa Marxologia: Filosofia e Estudos Confluentes - CNPq.
} 
que situem de modo disciplinar e sistemático, no sentido corrente dos termos. As discussões se encontram integradas na tentativa lukácsiana de articular a diferença específica que delimita e determina o ser da sociabilidade, de explicitar as principais categorias e conexões categoriais que perfazem o ser social. Nesse contexto, a argumentação é de caráter sintetizador ou integrador, na qual comparecem diversas questões e temáticas em diferentes ambiências discursivas e problemáticas. Lukács tenta assim superar a forma um tanto scholar que caracterizava o esforço anterior, inscrito, por certo, dentro dos contornos academicamente dominantes. No que respeita em especial à cientificidade marxiana, o que se percebe é a propositura de articular a exposição compreensiva da mesma a um conjunto de problemas acerca daquela definição do âmbito do ser social. Isso, inclusive pelo fato de que, acompanhando o que havia fixado em Para uma Ontologia, Lukács deixa claro que a compreensão correta das delimitações de ordem metodológica somente pode ser conquistada quando referidas permanentemente ao esforço de determinação ontológica dos problemas e das categorias. Desse modo, o tipo de mediações utilizadas pela ciência crítica marxiana apenas poderia ser explicitado na medida em que o fossem no âmbito das discussões e argumentações acerca dos elementos essenciais que, para o autor húngaro, caracterizariam a forma de ser precisa e específica do ser social.

Se por um lado, há o aditamento de uma melhor articulação do modo como Lukács entende a cientificidade marxiana em sua remissão à posição mais geral do problema das categorias, por outro lado, em não havendo uma aproximação minimamente monográfica do tema, a abordagem do mesmo se encontra mais diluída e imersa nas proposições lukácsianas. O modus sob o qual ele compreende a teoria de Marx como teoria não explícita com a clareza verificada em Para uma Ontologia do Ser Social. O empreendimento de exposição, ao buscar uma maior fidelidade à subsunção necessária do âmbito da cientificidade àquele dos problemas ontológicos, termina por padecer de uma organização mais disciplinada do tema. Afora isso, avoluma-se sobremaneira o que é uma particularidade do autor húngaro: a retomada de uma mesma referência temática (não somente textual) em diversos momentos da argumentação, uma vez que um determinado complexo problemático não receba tratamento "em separado", ainda que articuladamente, em relação aos demais. Deste modo, somente nas pouco mais de 40 páginas finais, a questão que preocupa o presente trabalho ganhou um enfrentamento mais detido e centrado. Não é necessário, obrigatoriamente, entender isso apenas devido a uma lacuna da concepção do texto, 
deveras devida também às condições pessoais nas quais Lukács, ao final da vida, veio a trabalhar, mas igualmente parece possuir conexão com o caráter do entendimento lukácsiano acerca da definição de cientificidade. Assim como na questão de método, só seria possível resolvê-la depois e em remissão ao próprio conhecer, analogamente a delimitação da teoria, de sua natureza, de seu escopo e de seus limites, somente poderia ganhar exposição na medida em que se tivesse percorrido reflexivamente seu próprio objeto; no caso, a analítica marxiana da produção social dos homens, em especial, da produção social da riqueza como capital.

Logo em momentos iniciais do texto, Lukács ratifica sua posição consolidada acerca da conexão específica havida em Marx entre princípios ou problemas ontológicos e o desenvolvimento da cientificidade. Assevera com clareza a impossibilidade de tomar as questões do conhecimento em independência, ou mesmo de modo prioritário, em relação aos temas da determinação do estatuto de ser do objeto. Não, por certo, do modo preponderante em que tal liame se pôs na tradição filosófica, mas tendo como elemento norteador a obrigatória referência das categorias ao momento da práxis concreta dos homens: "Dessa maneira, como sempre enfatizou o marxismo, a práxis, especialmente o metabolismo da sociedade com a natureza, se revela como o critério da teoria" (LUKÁCS, 2011, p. 46). Em outros termos, para o pensador húngaro, é de todo impertinente a suposição do assentamento da coerência científica de uma teoria ou de uma posição somente na forma como se dá a articulação interna destas. O caráter adequado de uma teoria não é um apanágio endógeno, efeito de uma armação lógica dos elementos, a qual responderia em sua autonomia pela sua correção e eficácia como instrumento ideal de aproximação dos fenômenos. Ao contrário, a justeza de uma propositura deriva igualmente de sua efetiva remissão ao complexo real, o qual, no caso particular da sociabilidade, tem na dinamicidade inerente um de seus traços mais essenciais. Ontologia ou posicionamento de talhe ontológico que, na obra marxiana, parte não de um princípio de inteligibilidade a priori e/ou absoluto, mas da compreensão dos elementos que perfazem o objeto inquirido e de sua concatenação objetiva. Os princípios, se estes existem, são postos e repostos continuamente pela apreensão da natureza do ser movens do objeto e são também medidos por esse metro. A posição marxiana se caracteriza assim por ser uma crítica dupla da coisa pela mediação teórica e desta última pela primeira. Criticismo de cunho bastante peculiar que abre a perspectiva do conhecimento como aproximação não fechada categorialmente e permite o rompimento efetivo com a lógica da 
pressuposição absoluta dos princípios conceituais. Nesse contexto, Marx se afastaria de modo crítico da tradição, ou seja, sem necessariamente a negar in limine, mas pondo o acento da condição do conhecimento fora do suposto círculo autônomo das faculdades e do discurso. O condicionamento do conhecimento não se daria então por uma pretensa conformação apriorística da subjetividade, mas pela existência concreta desta, como momento de um sujeito objetivo prático e social. A ontologia marxiana se faz assim crítica da tradição fundada no kantismo, aceita, até certo ponto, a advertência hegeliana de que o conhecimento não pode ter uma decisão acerca da sua possibilidade antes de sua própria efetivação.

O que não significa pôr a pressuposição do cognoscível numa substância racional, mas reconhecer o fato da existência concreta dos homens, a qual aponta o momento do saber como um de seus aspectos constitutivos, como ponto de partida e critério da teoria. O posicionamento marxiano, para Lukács, reporia em seu devido lugar central, a temática do ser, da definição do estatuto de realidade das categorias, mas não partindo de uma atitude teórica contemplativa, mas ativa para com o objeto. Assim:

a ontologia crítica de Marx não se limita a essa crítica criativa, que é criativa por não se limitar apenas a controlar, mas revelar novos processos realmente dialéticos. Ela parte, e desde o começo já partia, dos princípios mais profundos do ser social, da prioridade ontológica da práxis em contraposição à simples contemplação da realidade efetiva, por mais energicamente que esta se oriente para o ser (LUKÁCS, 2011, p. 71).

O descortino de novas dimensões e relações processuais aparece como uma resultante dessa síntese ativa entre o remetimento ao ser e o exame dos complexos particulares. Desta maneira, na cientificidade marxiana, o ser estaria sempre junto do que é, e o objeto permanece sempre, também na alçada da teoria, como processualidade ente. $O$ conhecimento dos objetos é humanamente possível na exata medida em que os próprios homens deles se apropriam, os modificam, os reconstroem e, neste sentido preciso, os criam como resultado de sua atividade objetiva.

Tema recorrente no pensamento de Lukács, a recuperação da apreensão da determinação ontológica da realidade seria então, au fond, o centro nervoso da tematização marxiana. Dimensão teórica esta esquecida, elidida pelo epistemologismo ou mesmo completamente perdida pelo evolver histórico do marxismo. O campo da tradição marxista não conseguiu apreender esta questão e a deixou à mercê das aproximações irracionalistas ou subjetivistas. Um cenário de devastação teórica que, em seu nível, expressa a natureza contraditória dos desenvolvimentos sociais recentes. 
Por isso, retomar o pensamento marxiano aparece como tarefa impositiva:

Assim, a abordagem ontológica do conhecimento da realidade ficou gravemente comprometida do ponto de vista teórico e sua renovação atual tem de recomeçar desde o início em certo sentido, e - com exceção da ontologia que fundamenta o método de Marx - só em raras questões isoladas pode recorrer a precursores históricos (LUKÁCS, 2011, pp. 39-40).

Num tempo em que a ontologia tornou-se sinônimo de uma discursividade duplamente interior, como fenomenologia do sentir do sujeito ou da linguagem como ser, Lukács acentua a necessidade de reconstruir a compreensão do pensamento marxiano em bases diferentes daquelas verificadas no marxismo corrente. Além disso, assinale-se também o diagnóstico extremamente grave da história do pensamento sobre o ser. Em sua contundência, o pensador húngaro excetua apenas a posição marxiana frente aos descaminhos dominantes em toda a tradição filosófica. Posicionamento este que é mais extremado que o presente em Para uma ontologia do ser social, porquanto situe não mais em Kant o momento de perda da perspectiva da questão, mas virtualmente o aponte como característica de todos os momentos históricos da ontologia como disciplina.

Evasão do problema que se repetiu sintomaticamente no marxismo, acompanhando a maré montante da elaboração teórica do século $\mathrm{XX}$, mas que teria começado bem antes, já no modo enviesado como Engels enfrentou alguns temas. Nesse contexto, com relação a Engels, Lukács se interroga: "[...] em que medida ele, nas questões metodológicas decisivas, se apossou com total coerência da transformação ontológica da imagem de mundo realizada por Marx, e em que medida se contentou em colocar Hegel 'materialisticamente de pé'" (LUKÁCS, 2011, p. 155). De certa maneira, a reação ao Neokantismo, dominante teórica e politicamente à época, como exigência ideológica do movimento revolucionário poderia ter contribuído igualmente para com o desentendimento do pensamento marxiano maduro e das relações críticas deste com as formulações hegelianas, em especial, a lógica do Espírito "namorada" como Darstellungsweise." Em referência a isso, é importante assinalar igualmente a observação lukácsiana, em parte mais avançada do texto, acerca dos óbices que concorreram para a resistência ao pensamento marxiano ou para a sua assimilação por vieses estranhos que lhe eram estranhos:

\footnotetext{
${ }^{1}$ Este problema em particular integrou o conjunto de questões da investigação empreendida pelo autor da presente discussão em seu trabalho de doutoramento, para a qual se remete o leitor. Cf. ALVES, 2012.
} 
[...] as condições de difusão do método e teoria marxianos também colaboraram para reforçar esses mal-entendidos e as resistências deles originadas. Nunca devemos esquecer que o marxismo, na origem, foi induzido a elaborar a peculiaridade de seu método em conflito crítico com Hegel, e sobretudo contra seus efeitos idealistas (LUKÁCS, 2011, p. 356).

Ou ainda, parágrafos à frente, particularmente acerca do papel efetivo das mediações conscientes no desenvolvimento dos processos sociais objetivos, Lukács nota com argúcia que:

A vulgarização do marxismo fez desaparecer precisamente esse problema decisivo do espaço de manobra. O materialismo vulgar, que muitas vezes se chama "ortodoxo", tentou fazer da objetividade dos processos econômicos uma espécie de "segunda natureza", isto é, a economia concretiza - de modo análogo - na sociedade as legalidades materiais (principalmente da natureza inorgânica) (LUKÁCS, 2011, p. 361).

O processo histórico de propagação da posição marxista, tanto acadêmica quanto politicamente, agiu no sentido de possibilitar a série de distorções perpetradas ao pensamento de Marx. Um dos mais decisivos, e originários, já encontrado em Kautsky, ${ }^{2}$ por exemplo, é a identificação sem mais do caráter de ser do social com aquele verificado na naturalidade. A indistinção de âmbitos do ser objetivo, a redução do caráter de objetividade à forma puramente natural, impediu o entendimento da posição científica marxiana, bem como a justa apreensão dos diversos problemas por ela enfrentados. O que teria agido no sentido de virtualmente converter a crítica marxiana da economia política em uma espécie de física do ser social. A differentia specifica consubstanciada pela articulação entre 0 agir consciente dos indivíduos/grupos - ainda que nem sempre com domínio correto das determinações e a historicidade constitutiva - e não meramente temporal ou entrópica -, acaba sendo algo não percebido e capturado como cerne da objetividade social.

Questão geral esta que se desdobra em outra de idêntica importância para Lukács: o estatuto das determinações mais abrangentes ou universais. Problemática de largo curso na história da filosofia, a delimitação da realidade das categorias tem, para o autor dos Prolegomena, um alcance de monta para a compreensão da cientificidade em geral. Para a sua discussão, recorre a Marx chamando a atenção para o fato de que no pensador alemão as categorias gerais não têm uma existência autônoma, mas, por outro lado, não são meros nomes ou figurações mentais. Estas possuem sim uma dimensão de realidade como determinações do ser dos objetos. É pautado por este parâmetro que coloca, exempli gratia, o exame das relações entre

${ }^{2}$ Cf. KAUTSKY, [s.d.], pp. 10-12; 17-20. 
gênero e singular: "Marx considerava a unidade inseparável entre gênero e exemplar como um fato fundamental do ser que deve incondicionalmente ser reconhecido e aplicado prática e teoricamente, sendo desnecessária a comprovação de seu ser" (LUKÁCS, 2011, p. 77). Generidade que significa a especificidade de uma dada forma existente de ser, e como tal corresponde à determinação precisa do modo pelo qual em dada esfera da realidade, um tipo de ente/processo se efetiva.

Não se ocupará aqui da discussão particular desenvolvida por Lukács frente e contra o modo predominante da tradição de entender este problema, mas se o alude para indicar a centralidade da definição categorial no pensamento lukácsiano. Forma de apreender e tratar este tema que tem um peso específico importante para a compreensão que Lukács possui da cientificidade marxiana. Como tal, o gênero não é, para ele, uma entidade ou substância que exista ao lado e autonomamente aos entes/processos, mas é o ser, como legalidade e escopo ônticos do existente. Mas não apenas, o é isto e somente pode sê-lo na medida em que o seja no existente. Tomando como apoio explícito a determinação marxiana das categorias como Daseinsformen, o autor húngaro a desdobrará argumentando contra as tendências de reduzir as categorias a meras formações ideais, unilateralmente, como produções intelectuais sem remetimento efetivo ao que existe. Categoria, consoante Marx, não somente tem um modo de existir ideal, mas "é ao mesmo tempo ser-objetivo, e a objetividade é a forma primordial concreta e real de cada ser, consequentemente de todo nexo categorial, que depois costumamos transportar para o pensamento como sua generalidade e expressar como a generalidade de seu ser-determinado". Afirma que é necessário não entendê-la, por conseguinte, como uma forma imputada pelo pensamento ao ser, como elaboração resultante de uma eleição de caráter metodológico ou instrumental. Conquanto seja expressão da legalidade no pensar:

[...] a generalidade não é nada mais nada menos que, em primeiro lugar, uma determinação do ser exatamente como a singularidade, e só porque ela, tanto quanto a singularidade, existe e opera no ser mesmo como determinação da objetividade, pode tornar-se - reproduzida pela consciência - um momento fecundo no pensamento (LUKÁCS, 2011, p. 261).

A existência no ser efetivo e atual que, por sua dependência objetiva com ele, apenas pode ser apreendido, compreendido e expressado justamente porquanto se penetre no âmago do objeto do qual a generalidade é determinação. Não se tratando, consequentemente de uma aplicação de um método ou esquema conceitual à multiplicidade dos entes/processos. Ao reverso, caberia encontrar na figuração do 
efetivo, no modo em que este se dá a cada momento, a vigência da determinação geral. O que desenha a rota de uma aproximação que precisa capturar as modulações históricas do objeto, a contextura atual, obrigatoriamente dinâmica e mutável, de que este se reveste. Historicidade, exprimida pela elaboração ideal das modulações temporais do ser, que não se opõe à natureza categorial da articulação que perfaz o existente atual; diversamente, é possível identificar em Lukács a postulação de uma complementaridade ontológica entre estes dois âmbitos. E isto a tal modo que "a concepção das categorias modais [em Marx] é direta e fortemente ligada à práxis humano-social" (LUKÁCS, 2011, p. 207). O que resultaria no desenho potencialmente distintivo da posição marxista em comparação com as demais, teórica e ideologicamente: "Precisamente porque o marxismo coloca o caráter histórico do ser mais decididamente no centro de seu método e da aplicação concreta deste do que qualquer outra teoria, ele é capaz de avistar, no desenvolvimento desigual, a forma típica dos processos histórico-sociais" (LUKÁCS, 2011, p. 226). Descontando-se certo otimismo lukácsiano - na medida em que confere aos epígonos o caráter teórico de Marx -, o que deve ser retido, neste momento, é a natureza fluida, mas permanentemente objetiva, das determinações categoriais.

Conferida assim de maneira bastante sumária, a fisionomia do empreendimento teórico de Lukács nos Prolegomena, apontando o enquadramento geral no qual aparece o problema tema deste trabalho, passa-se, na sequência, à explicitação e discussão do seu modo de entendimento do padrão científico que vige na obra de Marx.

Para apreender o modo como Lukács compreende o padrão teórico que configura a construção científica marxiana, é importante retomar, de saída, um aspecto acima mencionado, que diferencia a abordagem do autor húngaro do que comumente se observa no âmbito da epistemologia. O elemento central do que denomina método marxiano (ou marxista) não se situa no terreno procedimental stricto sensu, nem se resolve pela avaliação de uma propositura acerca da forma de entendimento da legalidade da ciência. Diversamente, o momento mais determinante é aquele no qual as categorias são definidas. As categorias não são somente mediações conceituais ideais, expressão unicamente da marcha do pensamento em sua suposta autonomia. Ao contrário, declara que "concebemos e tratamos as categorias não como princípios 
de formação lógicos ou gnosiológicos no interior do conhecimento, mas como determinações do próprio ser, já iluminamos alguns aspectos importantes do seu ser e atuar" (LUKÁCS, 2011, p. 228). Determinações estas que não são produtos do pensar metodicamente encadeado, mas de certo modo constituem apreensões conceituais da alçada do pré-teórico, da circunscrição da própria práxis. Ser e atuar tomados como unidade prática na qual o conhecimento se arrima e pelo qual se orienta, ou deve orientar-se, na tarefa de compreender racionalmente os objetos existentes. De modo sintético, historicidade e objetividade longe de oporem, constituem momentos interdependentes e dinâmicos da apropriação teórica da realidade:

[...] esse modo de se aproximar dos objetos, de suas formas de objetividade, só pode ser resultado do próprio processo histórico. Isso só pôde se formar aos poucos, na práxis e na sua teorização, seguindo o desenvolvimento econômico das forças produtivas, o recuo das barreiras naturais, a integração e socialização da sociabilidade etc. (LUKÁCS, 2011, p. 279).

Nesse sentido, Lukács pretende enfrentar o problema da delimitação da validade científica em termos, de todo, diversos daqueles colocados pela reflexão epistemológica. Essa propositura está em oposição, diga-se, en passant, inclusive às tentativas de inserir na lógica do ajuizamento das teorias o elemento histórico ou societário como, por exemplo, a de Kuhn e a das diversas sociologias do conhecimento. Notadamente, pelo fato de estas últimas tenderem a dissolver a objetividade do ser do objeto no caldo social ou linguístico, de converterem a resolução da questão do verdadeiro ou da aproximação teórica ao existente em um problema situado ou bem na arena do consenso dos pares ou bem no jogo de interesses em conflito. Por um lado, a objetividade se vê refém da articulação de pontos de vista em torno dos problemas trazidos pela emergência de um problema ou aspecto novo do objeto, ficando o objeto mesmo em um segundo plano com relação aos acertos em torno da teoria. Por outro lado, tem-se a incompreensão da cientificidade como produto de uma aproximação propriamente historicamente condicionada. Em detrimento da compreensão teórica se acentua unilateralmente o aspecto ideológico imanente, mas não único, que se apresenta no debate científico. Acerca desta última consequência, vale ainda ressaltar o quanto o verdadeiro se torna mero simulacro dos interesses, a posição da cientificidade um puro embuste, tornando-se virtualmente inapreensível o andamento, por certo irregular e eivado de contradições, da construção do conhecimento acerca dos vários âmbitos ou níveis da realidade que efetivamente se verificou. A história se vê transtornada em simples jogo de poderes e as soluções 
contraditórias em resultados de uma conspiração. Tal modo de pôr os problemas não permite visualizar, exempli gratia, a coexistência opositiva, mas existente entre posição de classe do cientista, com suas limitações de angulação, e produção efetivamente objetiva de conhecimento. Fato este que se expressava frequentemente nos juízos críticos marxianos acerca dos economistas clássicos. Tais proposituras reflexivas, conquanto pretendam-se críticas, apenas alcançam o nível, quando muito, da iconoclastia teórica, exatamente ao celebrarem como ponto essencial o que procuravam denunciar: a perda da objetividade. A inexistência da objetividade é ela mesma afirmada, numa versão extremada do interdito kantiano à Ding an sich, como componente característico e irremediável da cientificidade. A ciência se converteria então em mais um mithos, uma narrativa entre outras, e talvez como as outras. Lukács a esse respeito assevera que:

Com isso, chegamos mais uma vez ao ponto em que se torna bem visível o contraste entre Marx e o pensamento burguês em relação às categorias do ser. Para Marx, como mostramos repetidas vezes, as categorias são "formas do ser, determinações da existência", isto é, são partes, momentos, moventes e movidos daquele grande processo irreversível que costumamos chamar, da maneira mais geral, do ser (LUKÁCS, 2011, p. 289).

Ao arrepio da preponderância acadêmica e prática dos modos de pensar a cientificidade que dissipa a objetividade em condições subjetivas e ideológicas, Lukács pretendendo-se arrimado no pensamento de Marx propõe uma retomada categorial do ser. Ressalte-se que de maneira nenhuma pode ser essa reposição do ser na esfera do pensar análoga àquela propugnada por Heidegger frente ao que ele chama de esquecimento do ser. Primeiramente, porque para Lukács ser é sempre ser de processos entes, "simples" determinação, das Sein num sentido "puro", distante ou em separado daquilo que efetivamente é. Em segundo lugar, em virtude do acesso ao ser não se dar pela via de uma contemplação teórica passiva ou do sentimento, mas como reflexão remetida e cotejada com a práxis social concreta, suas possibilidades, problemas e aporias. A cotidianidade não se reveste para o autor húngaro do caráter de inautenticidade. É, ao contrário, o terreno do efetivo do qual se parte e que deve ser adequadamente compreendido, revelado, destrinchado, esclarecido e explicitado em suas determinações essenciais não visíveis.

Como formas do ser, para Lukács, as categorias têm uma existência efetiva nos complexos relacionais existentes, na medida em que os delimitam e particularizam. São formas segundo as quais se concatenam relações e nexos entre elementos na figuração real dos objetos, fornecendo-lhes uma determinada articulação. Como exemplo desta 
vigência ôntica das categorias, recorre ao caso da elucidação do trabalho abstrato como determinação da riqueza na crítica marxiana da economia política. Ao contrário de poder ser entendida apenas como uma abstração, figura ideal resultante da operação mental que destaca e explicita caracteres comuns aos tipos de trabalhos concretamente efetuados, possui objetivamente uma operacionalidade fática (Cf. LUKÁCS, 2011, p. 276). Ou seja, circunscreve o modo de existência concreto e particular dos produtos da atividade humana sob a relação social capital. É um dado modo de ser do ser da produção social, da interatividade por meio da qual a vida humana se mantém e se reproduz como tal. Enfrenta aos indivíduos em sua existência social real como lei de funcionamento das suas relações, sendo completamente objetiva frente a eles. As formas, como determinação dos processos sociais, configuram ou dispõem os componentes da interatividade societária numa dada dação de existência específica e historicamente condicionada. Como tais, têm vigência objetiva como forma de um processo social de existir das coisas:

Por isso, a "objetividade espectral", tanto como desencadeadora quanto
como consequência, é para a práxis (por isso também para o pensar) de cada
ser humano que vive na sociedade algo tão existente quanto a própria
realidade material do trabalho concreto. Valor de uso e valor de troca têm
no ser social uma coexistência real dialeticamente determinada,
independentemente de como se constitui a objetividade de cada uma,
tomada de maneira isolada (LUKÁCS, 2011, p. 276).

Utilizando a expressão objetividade espectral, Lukács intenta capturar e explicitar essa dimensão determinativa das categorias, num movimento teórico que se cumpre duplamente: negando, de uma parte, a unilateralidade nominalista ao agnosticismo teórico presente em certas reflexões epistemológicas, e, de outra parte, acentuar a sua vigência como forma do ser, não redutível aos elementos físicos ou particulares do complexo. As formas são expressas de uma determinada modalidade de complexidade que emerge no curso de um processo de desenvolvimento, particularizando o desenho e o escopo de uma articulação categorial real. Esta última não é concebida, portanto, como resultante de uma operação do intelecto, mas sim ao modo de um existir determinado da coisa por si mesma, que o pensamento precisa aproximadamente espelhar e explicar.

Afirmação da ordem objetiva de determinações que põe em xeque a pretensa autonomia, ou precedência, da racionalidade em relação ao existente, a qual é sustentada como ponto de honra na tradição filosófica pós-kantiana. Seja no sentido kantiano, em que a razão permanece como instância autônoma frente ao empírico, 
forma transcendental de ajuizamento, seja no sentido hegeliano, em que a razão tem uma conaturalidade com o mundo, desdobrando-se como finitude empírica, a determinação categorial aparece sob o modo de uma dação externa ou ascensional em frente à coisa finita. No pensamento marxiano, as categorias possuem, ao contrário, existência no e pelo efetivamente dado. Nesse contexto, adverte que em relação à especulação da Ideia de que frente a Hegel: "Marx combate a tendência abstrata da logicização hegeliana idealista da realidade, que distorce o ser" (LUKÁCS, 2011, p. 270). Pois, se há a captação da historicidade do ser em Hegel, esta se converte num golpe de determinação do processo em processualidade substancial, transmutando, por conseguinte, a objetividade histórica em episódio do Espírito. O que Marx denuncia como invólucro místico a envolver o que há de racional na formulação hegeliana. $O$ caráter dinâmico da existência dos complexos reais, em Marx, não seria transformado em sujeito. Como ente ou pôr-se subsistente se admite apenas o finito, sendo as categorias determinações de uma específica articulação, segundo graus e diferenciações condicionados e circunstanciais. Não é apenas o tema de uma cientificidade especializada - ainda que não o exclua como tal - mas é antes a forma dinâmica e processual do ser das coisas. Assim:

\begin{abstract}
Historicidade no sentido de Marx é, em contrapartida [à "especialização" da pesquisa histórica como mero ofício acadêmico sobre um problema particular e isolado], um princípio universal, chamado não apenas a apreender aquele tratamento científico do ser, especialmente do ser social, mas também, e, sobretudo, a influenciar, dirigir, de modo correspondente, as atividades humanas (LUKÁCS, 2011, p. 292).
\end{abstract}

Universalidade de princípio que urge ser percebida como geral vigendo na e em nome da complexidade atual dos processos entes. Não, evidentemente, como universalidade substancializada, como entidade real ao lado dos existentes. Mesmo o capital em geral, exempli gratia, para o qual Marx identifica um modo de existir efetivo frente aos capitais em sua dispersão e competição, apenas é tal como uma dada forma ou função social objetiva assumida pelo dinheiro no processo de produção/circulação do capital. É ele mesmo um caráter socialmente determinado e historicamente engendrado em sua validade e eficácia. Desdobrando essa acepção de historicidade como caráter inerente ao ser como tal, Lukács põe em relevo outro tema importante de sua reflexão: a complexidade inerentemente dinâmica do ser. O ser não é compreendido como "essência" a que devém atualizada, nem como abstração, mas é um processo de ser de categorias dinamicamente articuladas. Assim, "tudo - também o material-'coisalmente' dado - em seu verdadeiro ser é um processo irreversível de 
complexos" (LUKÁCS, 2011, p. 292). A própria materialidade em sua existência concreta, conforme se apresenta "aí" é, portanto, um complexo, um conjunto integrado de categorias que se remetem entre si e, em sua reciprocidade de determinações, perfazem o modo de ser do ser daquilo que é: dos processos entes. Destacando esse caráter de interdependência determinativa das categorias, Lukács afirma nas linhas que se seguem:

[...] tais processos nunca podem possuir um ser isolado, "precisamente" separável de outros processos, que entre eles sempre vigoram influências recíprocas intensas ou extensas, fortes ou fracas, de modo que a autêntica constituição do seu ser apenas pode ser concebida de maneira adequada no contexto do processo em seu conjunto em que ontologicamente se sintetiza, e também no interior da sociedade em seu conjunto como totalidade processual (LUKÁCS, 2011, p. 292).

Os aspectos apenas existem isoladamente no modo como são tomados e inquiridos pela atividade cognitiva, não no nível de sua existência efetiva e objetivamente dada. Aqui se assinala um lado da questão importante para a cientificidade em geral, tão antiga quanto a reflexão sobre as coisas e as suas "partes", que ainda atualmente possui pertinência. Basta mencionar, brevemente, o quanto a investigação da natureza em seus constituintes fundamentais, na física das partículas/altas energias (no campo dos G-elétron/volts), fornece de indícios para essa observação geral, porquanto as partículas tenham uma existência isolada por períodos extremamente breves, decaindo logo a seguir. Este problema particular demonstra a competência, rara na tradição filosófica recente, que Lukács possuía para atinar com possíveis questões de princípio, ontológicas, trazidas pelos desenvolvimentos científicos e tecnológicos.

Talhe reflexivo este, a comunicabilidade com a cientificidade de ponta, que o próprio autor húngaro aponta na obra marxiana. Nesse contexto, destaca também a cooperação, na e pela distinção, entre filosofia e ciência. Tais formas da cognição não se consubstanciam, ou se resumem, a "campos" da atividade de conhecimento ou "disciplinas acadêmicas", mas integralizam o ato de apreensão racional da efetividade. Não são concorrentes, mas complementares e podem estar presentes num mesmo esforço de cientificidade ao modo de níveis ou esferas. O que se daria de modo paradigmático no pensamento de Marx:

O grande feito metodológico de Marx é que ele colocou esse contexto de cooperação objetivamente indispensável, mas até então nunca realizado, entre ciência e filosofia, esse complexo de forças, no centro da metodologia de toda práxis e do conhecimento que a acompanha e estimula - referindo ambas à copertença processual necessária entre ser, categorias, práxis e 
conhecimento, remetendo-as à historicidade geral que lhes dá fundamento comum. Com isso - tendo por base a historicidade universal, o estatuto do ser das categorias, da práxis como órgão de sua apreensão -, supera-se a velha contraposição entre ciência e filosofia (LUKÁCS, 2011, p. 298).

O que significa dizer que a cientificidade marxiana desconhece a - para usar uma metáfora grata a Lukács - "muralha chinesa" contemporaneamente erguida entre estas duas modalidades de racionalidade. Conhecimento científico e reflexão filosófica normal e preponderantemente são apresentados no discurso corrente da epistemologia como excludentes ou opositivas. São momentos de uma dada unidade cognitivo/discursiva acerca do mundo. O âmbito da pesquisa das legalidades particulares e fenomênicas conquanto tenha forma e escopo diverso não resulta por isso em espaço estranho e refratário à teorização sobre os aspectos mais gerais da realidade. Igualmente, este último ambiente teórico não nega a particularidade, nem toma de maneira unilateral a aproximação das ciências, ainda que reconheça seus limites; mas dela se nutre e depende. Não é procedente ao filosofar a propositura de um entendimento apriorístico que determinasse de antemão os rumos da efetividade, a partir do desdobramento de um princípio de inteligibilidade, por exemplo. O teor do padrão de cientificidade da obra marxiana indica uma específica forma de relação que há, segundo Lukács, entre conhecimento teórico e sua contraparte reflexiva:

[...] falando metodologicamente, nada mais, nada menos, que todo o conhecimento científico deve se orientar pelo conhecimento filosófico, e todo conhecimento filosófico pelo científico, e de modo ininterrupto extravasar-se, a fim de conceber, em pensamento, o ser em sua articulação categorial e as categorias como determinações internas do ser (LUKÁCS, 2011, p. 311).

Lukács chama, adequadamente, essa articulação de momentos reflexivos e analíticos de "fundamentação científica" e não fundamento ou fundamentação epistêmica ou teórica. $\mathrm{Na}$ medida em que esta deve remeter ao caráter ou estatuto determinativo das categorias, a dúplice existência destas como, primeiro, momentos do ser, do efetivamente dado como ente/processo, da síntese Dasein, e, em segundo lugar, elementos de uma síntese teórica (Cf. LUKÁCS, 2011, p. 317).

Nesse sentido, toda forma de cientificidade é, e permanece sendo, um exercício post festum. Como tal, a elaboração científica de Marx também apresenta esse irremediável caráter de subsunção ao objeto, às suas determinações e processualidade de ser. Construção, elaboração e formulação da teoria são passos que somente podem ser efetivados na medida em que a constituição histórica mesma do objeto o permita. A historicidade praticamente configurada da objetividade social impõe uma modulação mais particular ainda e exige o exame detido da malha categorial que configura o 
objeto como objeto. Abundam na obra marxiana casos em que o filósofo alemão indica como óbices da efetiva captura científica do problema exatamente a contextura incompleta da forma social que se desenvolve por meio das transformações da sociabilidade e da atividade produtiva no correr do tempo. Neste caso, a dedutibilidade se encontra necessariamente limitada pelo caráter dos desenvolvimentos objetivamente dados. Isto vale com especial ênfase para a sociabilidade, ainda que não apenas para ela. Mesmo na naturalidade, ainda que vigorem leis sob uma forma "dura", tal maneira de dar-se não exclui a casualidade ou as aporias que desembocam em processos imprevistos por uma predição de longo curso - pense-se especialmente no terreno dos seres vivos e da evolução das espécies. Nesse sentido:

Esse domínio total do princípio causal em todos os processos que constituem cada ser não permite senão um conhecimento post festum: que se volta para processos já decorridos, por isso, em um tratamento histórico-científico baseado em resultados fáticos, insuperáveis dos processos. Da historicidade do processo total do ser nasce, portanto, a exigência metodológica da cientificidade precisa dessa investigação (LUKÁCS, 2011, p. 294).

Este filão conceitual demarca de maneira conspícua a distinção inegociável do talhe investigativo propriamente materialista frente às elucubrações da especulação filosófica. Desse conduto, a fluidez do conhecimento, seus rumos possíveis, é determinada pela marcha da coisa e não daquela de uma racionalidade autoposta. Assim, as elaborações marxianas acerca de totalidades processuais não têm sua legitimidade conferida por uma mera caução metodológica ou de coerência teórica interna. São, ao reverso:

[...] senão constatações de fatos post festum do próprio desenvolvimento, em que tanto a preservação, ou melhor, a permanente reprodução de determinados componentes em geral existentes há muito tempo, como o ininterrupto surgimento de novas objetividades, novas formas de processo etc., podem ser observados (LUKÁCS, 2011, p. 294).

A cientificidade marxiana, em sua empreitada de apreensão de conexões efetivas e de direções tendenciais possíveis se mostra como:

[...] um duplo movimento intelectual: de um lado, o conhecimento mais preciso possível dos seus próprios movimentos concreto-reais, em sua imediata propriedade concreta, de outro lado - sem querer superar abstratamente esse tipo de constatações -, o conhecimento dos momentos comuns, que neles operam, e que, sem anular essas propriedades, instauram entre eles uma unidade dos seres processuais, que os transformam em momentos de toda formação econômica (LUKÁCS, 2011, p. 310).

Uma síntese pensada duma síntese real, de uma unidade das (e nas) diferenças. O que, para Lukács, contribuiu no sentido de o pensamento marxiano evitar as 
soluções absolutas da totalidade metafísica, bem como aquela do logicismo dialético hegeliano que, inclusive, abole a própria autonomia e irredutibilidade das figuras concretas, finitas e objetivas, em benefício da sua integração como mero "momento" da autoexplicitação do Espírito ( LUKÁCS, 2011, pp. 312-313). Nesse diapasão, é possível rematar o presente desdobramento com a proposição sintética lukácsiana segundo a qual, "O método de conhecimento é, pois, determinado pela constituição objetiva (ontológica, categorial) de seu objeto" (LUKÁCS, 2011, p. 327).

Esse caráter distintivo da cientificidade marxiana não nasceu, para Lukács, de um golpe, obviamente, pronto e acabado; tem ele também uma história. Construção de um standard científico que se procedeu na temporalidade vivida de um pensamento que buscou enfrentar a efetividade do mundo e forjou suas categorias no curso deste embate. Assim como em Para uma Ontologia, o texto lukácsiano em tela tomou o problema da constituição do padrão marxiano de pensar de maneira diversa daquela verificada na tradição marxista. Desvencilhando-se da tese de um corte absoluto, não obstante pontuando as descontinuidades de monta, de acento ontológico, Lukács almejou apreender a integralidade do percurso, talvez pagando um pesado ônus ao inverter a lógica dominante. Em certos momentos, identificando os germes da obra madura, em que estes ainda não poderiam estar senão como dúvidas ou incongruências com relação ao feitio teórico que conformava o pensamento de Marx nas suas épocas germinativas mais recuadas. Não é possível atribuir ao período de formação intelectual acadêmica e à militância na Rheinische Zeitung aproximações cuja essência em muito distam e se opõe ao que ficará conhecida historicamente como obra marxiana. Não obstante, vale a pena ressaltar a acurácia do autor húngaro ao procurar ligar pontos, em que a corrente althusseriana, exempli gratia, vê tão somente esgarçamento, a partir da postulação de uma simples découpage. $\mathrm{E}$ isso, em referência à querela mais que célebre das relações críticas de distanciamento para com Hegel. Em parte delimitando o sentido da posição marxiana, em parte conectando 1857 a momentos anteriores da elaboração desta, Lukács observa:

Aqui se vê com que seriedade o jovem Marx falava ao designar a objetividade (em última análise: a concretude real) pura e simplesmente como sinônimo do ser. A objetividade não é uma determinação (ou um complexo de determinações), seja segundo o ser, seja pela consciência cognoscente, algo acrescido ao ser, formando-o, e deve ser reconhecida no sentido rigorosíssimo: todo ser, na medida em que é ser, é objetivo. O fato de que, portanto, no pensamento, o concreto apareça como processo de síntese, é uma aparência à qual, como mostra Marx nas considerações logo a seguir, até Hegel sucumbiu. O concreto, em suma, é ontológico e justamente por isso a consideração ontológica não o assume como resultado, mas como 
ponto de partida (LUKÁCS, 2011, p. 326).

III

O que é visível na análise da cientificidade marxiana procedida por Lukács é o reconhecimento de uma conexão essencial entre a constituição da coisa como coisa e a formulação do conhecimento teórico acerca dela. A subsunção ativa ao objeto é uma démarche clara em comparação tanto à especulatividade idealista quanto ao talhe empiricista dos procedimentos que resumem a ciência à medição estatística de fenômenos. O que não significa, no entanto, que haja para Lukács uma homologia entre o modo pelo qual o ente/processo se efetiva como tal e aquele por meio do qual o sujeito humano se apropria de sua lógica de existência: "esse processo nunca pode ser idêntico àquele do ser, nem simplesmente imitar os seus processos" (LUKÁCS, 2011 , p. 327). Essa disparidade entre os dois processos resulta numa certa "autonomia" do processo do conhecer, mas não no sentido usual da teoria do conhecimento, como advindo de uma suposta autossustentação da razão. Ao contrário, essa distinção de âmbitos tem por consequência que o exercício da racionalidade tenha de se orientar pela predicação inerente do objeto, e não o inverso, como ocorre no metodologismo em geral, na submissão do objeto a um conjunto de princípios metodológicos e epistêmicos autorreferenciados. Daí:

[...] segue-se que os 'métodos' aí aplicados, as determinações assim obtidas, não têm nenhum valor de conhecimento baseado em si mesmo, muito menos podem servir como 'modelos' para a constituição do próprio ser, como costuma ocorrer devido ao predomínio da teoria do conhecimento. E que, ao contrário, só o grau de aproximação à constituição ontológica da respectiva objetividade a ser examinada pode fornecer o critério de correção ou falsidade de um modo de conhecer (LUKÁCS, 2011, p. 326).

Segundo Lukács, o que vigora com respeito a essa questão é a "prioridade incondicional do ser em sua respectiva objetividade" (LUKÁCS, 2011, p. 327).

Essa prioridade ontológica teria uma vigência teórica robusta na medida em que se exerceria como caráter delimitador do estatuto das próprias categorias como formas ideais dotadas de universalidade. O exemplo referido por Lukács é o da discussão marxiana acerca da validade da categoria produção em geral, encontrada na Introdução de 1857, no trecho em que Marx responde afirmativamente com relação à pertinência razoável desta abstração:

Esse reconhecimento de uma universalidade do ser, isto é, uma persistência continuada de momentos importantes no processo irreversível das transformações, é importantíssimo para a ontologia de Marx. Com isso, tal reconhecimento vai além da dinâmica abstrata de um "tudo flui" no sentido de uma dinâmica heraclitiana abstrata, e mostra que a nova ontologia pode 
e deve reduzir a antiquíssima oposição de princípios, insolúvel do ponto de vista lógico ou da teoria do conhecimento, de Heráclito e dos eleatas, a uma cooperação contraditória e desigual dos dois momentos do processo irreversível no ser (LUKÁCS, 2011, p. 328).

O que aparece em Marx sob a designação de aspecto comum a muitos, assume, ainda que não de modo necessariamente imputativo, um caráter de decidida universalidade em sentido forte, como persistência continuada de momentos de um dado itinerário processual, no decorrer da existência atual historicamente em configuração da forma específica da interatividade social. Vale assinalar, além disso, que, como é comum nos textos lukácsianos, a elaboração marxiana aparece sempre contendo, ainda que não como intenção explícita ou problema propriamente dito, os indicativos para a solução de uma determinada contenda ou aporia da tradição filosófica.

A vigência de momentos comuns de modo multideterminado em complexos reais é teoricamente expressa pelo autor húngaro como "compenetração recíproca na dialética entre autonomia, em princípio, e dependência multilateral de uma em relação à outra em cooperação concreta" (LUKÁCS, 2011, p. 326). Ou seja, importa a Lukács delimitar com a máxima precisão possível, a partir das indicações marxianas, uma dada configuração geral que presida, não obstante de forma dinâmica e aberta, o conjunto dos nexos categoriais que põe a efetividade dos processos de ser. Modalidade que pode ser indicada como presente em várias estruturas reais que definem a especificidade da sociabilidade como zona ou momento ontológico da efetividade. Nesse sentido, Lukács destaca como figuração exemplar a análise marxiana da interpenetração das categorias evidenciadas no complexo da produção social. Produção, consumo, troca e distribuição surgem no interior da tematização de Marx de modo de todo diverso daquele observado no encadeamento lógico e/ou superficial dos economistas, como momentos sequenciais correspondentes a níveis de universalidade. As quatro categorias constituem um todo da produção, no qual a presença de uma seria sentida como momento de determinação condicionado no âmago de uma outra. Em termos categoriais:

[...] tanto o complicado sistema dos efeitos recíprocos concretos é elaborado nesse nível de generalidade, quanto devem ser relacionados ininterruptamente, com isso, os momentos singulares da produção, que não entram apenas em interações recíprocas concretas, historicamente mutáveis, mas também se ancoram em contextos sociais gerais, e que por sua vez retroagem sobre eles (LUKÁCS, 2011, p. 330).

Nesse mesmo diapasão de conferir a Marx a indicação de aspectos extremamente 
gerais com relação à determinação das categorias está, sem dúvida, a afirmação lukácsiana de que "a determinação do ser marxiana da história como característica fundamental de qualquer ser é uma teoria universal, válida tanto na sociedade como na natureza" (LUKÁCS, 2011, p. 331). Lukács tenta de pronto afastar, na sequência, qualquer acepção metafísica ou de que a historicidade como caráter geral de toda a forma do ser seria uma generalidade teórica abstrata então "aplicada" ao estudo do humano (como se apresenta na vulgata staliniana, por exemplo, ou mesmo no entendimento acadêmico da teoria do conhecimento). A historicidade vigeria como determinação essencial do movimento processual dos momentos do ser em seus vir a ser particulares. Assim, Marx "quando fala de processo histórico, via de regra se refere a todo o processo irreversível do universo, do qual em determinadas circunstâncias (em última análise também casuais) se desenvolve o período histórico do ser humano, trabalho, sociedade etc. como nova maneira do ser" (LUKÁCS, 2011, p. 331). É importante frisar aqui como elemento importante, abstraindo-se no limite a adequação ou não de tal ancoragem na obra marxiana, a quase identidade afirmada por Lukács entre historicidade e irreversibilidade. Conexão essencial que exprime filosoficamente uma experiência vivenciada, tanto no nível quanto naquele da cientificidade: o da seta do tempo. Nesse sentido, a temporalidade objetiva, expressa categorialmente como história se reveste de um sentido determinativo central para o entendimento da estrutura do ser da realidade, bem como para a apreensão do movimento multivariegado de figurações e formas de existência concreta. Desse modo, pretendo consonar com o pensamento marxiano, "[...] a caracterização das categorias como formas de existência, determinações de existência da objetividade como marca inseparável de todo ser, pertence às determinações fundamentais resultantes da historicidade geral como característica ontológica de todo ser" (LUKÁCS, 2011, p. 332). Opera-se aqui no registro de uma dupla recusa do princípio basilar da tradição moderna da filosofia da subjetividade. Por um lado, não se persiste numa separação absoluta ou dicotômica dos âmbitos da naturalidade e da sociabilidade. Por outro, em consequência, intenta-se a determinação de categorias que, num nível extremo de abstratividade - ressalvada sempre a existência concreta particular destas em cada complexo efetivo de ser, possam delimitar a objetividade do ente/processo como tal em sua efetividade. O humano mesmo aparece como momento do ser, da existência de modos objetivos de esta-aí, como uma dada configuração particular, no quadro da qual as categorias do ser assumem feições diferenciadas e virtualidades, sem que um 
dos seus aspectos, por mais distintivos que sejam, ganhem uma autonomia fantástica e metafísica (como o cogito, exempli gratia).

Desse modo, a constituição de uma compreensão ontológica de mundo não se identifica com confabulações em torno de supostas formas etéreas ou determinações absolutas imutáveis. Ao contrário, desvela formas de determinações que se põe aquém e além daquelas puramente conceituais, da assimilação teórica da efetividade como momento de uma prática científica. A concretude das determinações existe e se faz valer para Lukács mesmo no interior do contexto circunscrito pelo experimento, pela construção, observação e medição controladas - "depuradas" - dos fenômenos conforme os controles e protocolos procedimentais vigentes em cada modo de cientificidade. Conjunto de formas de relação objetivas produzidas e objetivamente postas ao cientista, as quais, conquanto apresentem um isolamento com relação às "condições normais" ou cotidianas da prática vivida, não são pura e simplesmente resultantes de uma posição epistêmica ou produtos da consciência, mas no experimento, estas permanecem subsumidas à vigência, ainda que especial, do âmbito do ser como concretude de determinações. Assim:

Não importa a relevância dos momentos conceituais na preparação do experimento, isso ainda pode mudar no caráter do resultado como um desvendamento de contextos do ser verdadeiros. Isso já se vê quando o experimento é chamado a confirmar ou refutar precisamente as "hipóteses" que fundamentam a "depuração" do ser. A decisão sobre a verdade do pensamento também é tomada, aqui, pelo próprio ser (LUKÁCS, 2011, p. 332).

Lukács, por conseguinte, nega também aqui a presumida prevalência, ou mesmo a preponderância, da coerência interna, lógico-matemático-formal, como o único requisito a ser preenchido por uma formulação teórica. Esse vício idealista comum à epistemologia contemporânea tende a afirmar-se como um verdadeiro ponto de honra na interpretação da atividade científica. O modelo teórico, independentemente de sua conformação estrutural, torna-se o momento determinante, ao qual se submete a efetividade do objeto investigado. Daí a afirmação muito comum à teoria do conhecimento segundo a qual as categorias no fim das contas não remeteriam a nenhuma instância objetiva. A natureza aproximativa do conhecimento se vê identificada com uma mera aplicação convencional de construtos ideais aos fenômenos, sem os conceitos, que perfazem os primeiros, possuam necessariamente a menor correspondência ontológica com as determinações vigentes por-si destes últimos. Observação que parece ter validade no que tange à delimitação do padrão 
científico que formata as elaborações marxianas. O efetivo continua sempre a viger, por meio e na diferenciação dos vários momentos integrantes do processo do conhecimento, no curso do qual se supera a aparência imediata dos fenômenos é superada em benefício do esclarecimento das determinações que se expressam como Erscheinungsformen da vida cotidiana da sociabilidade do capital. Não se trata de uma forma de modelagem abstrata, mas de abstrações que capturam momentos determinantes e ganham concatenação reproduzindo, no nível do pensamento, a articulação categorial particular a cada conformação real.

A esse respeito, com referência ao tema das relações entre 0 desenho da cientificidade em geral e a identificação dos elementos mais essenciais daquela de Marx, assinale-se como a remissão a supostos experimentos mentais ou ideais como variável operante do modus marxiano de fazer ciência, observada em Para uma Ontologia do Ser Social, desaparece completamente. As abstrações não teriam uma articulação puramente interna ou, ao menos, determinada também por uma dada lógica que thes poderia ser atribuída, mesmo que provisoriamente. Ao reverso, o concretamente existente continua sendo a tribuna efetiva do juízo de cientificidade das categorias. A contextura própria das categorias pensadas em comparação com aquela das determinações existentes como momentos da objetividade dos processos, não obstante seja preservada e identificada como elemento de distinção, entretanto não serve como álibi para afirmação duma forma qualquer de autonomia plena do ideal e de seu suposto nómos em sentido absoluto.

Nesse sentido, a analítica marxiana desvela o processo de produção, com seus momentos e circuitos característicos, como uma dada interatividade social que engendra formas particulares de existência, não somente dos objetos ou de processualidades em sua concretude imediata, mas desta como uma dada conformação específica. O problema da elucidação e da explicitação teóricas das Daseinsformen é, por conseguinte, o centro das preocupações da crítica marxiana da economia política. Um dos casos mais paradigmáticos a esse respeito é o das objetividades espectrais, conforme o enuncia Lukács. O econômico se reveste nesse diapasão de um caráter diverso daquele que parece ter na imediaticidade da produção de mercadorias. Tratase, portanto, de uma analítica das formas sociais concretas de existência dos resultados da atividade objetiva/objetivante dos indivíduos sociais; de como as relações sociais nas quais e por meio das quais transcorre a interatividade social configura e delimita a existência atual dos elementos da vida humana. $O$ caráter de ser do ser social não 
se resume à materialidade ou à concretude direta de determinidades, mas contempla como determinação dessa mesma objetividade a forma societária específica pela se particularizam e se determinam as coisas e processos produzidos. Forma societária que recebe seu ato de dação de efetividade mediado pela atividade sempre consciente, embora nem sempre com consciência disso, dos homens. Nesse sentido, o autor húngaro distingue a forma objetiva da sociabilidade daquela observada na naturalidade, a mera gregariedade. Não se trata de um âmbito governado de modo preponderante por uma causalidade muda, mas travejado por um espaço de "manobra para o surgimento e a efetivação de novas decisões alternativas relativamente aos pores teleológicos realizados pelos seres humanos" (LUKÁCS, 2011, p. 360).

IV

A efetivação do curso de exame acima exposto permite a Lukács operar uma delimitação de alcance geral, bastante abrangente da cientificidade marxiana:

[...] conforme constata Marx, todo conhecimento é apenas uma aproximação mais ou menos ampla do objeto. E os meios espirituais e materiais dessa aproximação são, por sua vez, determinados pelas possibilidades objetivas da respectiva sociabilidade. Objetiva e subjetivamente, pois em todo conhecimento só pode se tratar de aproximações (portanto, de algo relativo) (LUKÁCS, 2011, p. 360).

Esta compreensão engendra necessariamente um posicionamento crítico em resposta às pretensões sustentadas pela oficialidade marxista existente em seu tempo, tanto na academia quanto nos movimentos prático-políticos. Um dos aspectos da crítica lukácsiana ao soi-disant "marxismo ortodoxo" reside exatamente no desentendimento do sentido da categoria da possibilidade objetiva, na transformação da ciência histórica numa física social. Porquanto o objeto da cientificidade social se veja transmutado em uma segunda natureza, a sua compreensão teórica converte-se numa construção conceitual em que não há espaço para a apreensão da diferença específica do ser social em sua objetividade material. $O$ que conduz o pensamento à busca de supostas "leis naturais" do desenvolvimento histórico, no sentido de conformar a sociabilidade como um tipo de realidade naturalmente dada. Como exemplo mais eloquente desse entendimento enviesado tem-se, segundo Lukács, a concepção mecânica, pressupondo uma causalidade direta, unívoca e unidirecional entre o campo da economia e aquele das formas de consciência; o famoso problema do nexo entre "base" e "superestrutura". Liame este tido pelas proposituras dominantes, como baseado quase numa exclusão. Contra essa posição de viés, Lukács chama a atenção para o fato de que: 
Um exame mais aprofundado dos processos econômicos no ser social, segundo o método de Marx, deveria mostrar que não se trata simplesmente desse pôr-em-movimento. É verdade que, já com isso, o momento econômico do ser social cessaria de ser puramente material no sentido da física ou da química. Mas esse entrelaçamento íntimo vai muito além. Anteriormente, já comentamos como Marx fala de "objetividades espectrais" em análises puramente econômicas no interior da economia, expressando claramente que mesmo os modos de existência puramente econômicos não mostram uma constituição material homogênea. Por certo, seria muito instrutivo seguir exatamente essa indicação em uma análise ontológica detalhada do mododo-ser econômico (LUKÁCS, 2011, p. 362).

Objetividades espectrais que remetem, como vimos, na aparente natureza paradoxal da formulação para o problema da determinação pela forma social, questão que efetivamente compõe o arsenal teórico marxiano e participa ativamente da produtividade analítica de sua cientificidade. Formas da objetividade que engendram outras de caráter puramente ideal, mas que desempenham uma função social efetiva e têm consequências para momentos necessários da concretização da produção, como é o caso do preço. Além disso, lembra Lukács que essa conexão entre o ideal e o real não se dá somente no sentido de que o primeiro participa do segundo, mas igualmente vice-versa. As instâncias de poder ou de expressão ideológica não podem prescindir, e verdadeiramente mobilizam, da "crítica das armas": "Basta lembrar as formulações espirituosas de Max Weber, de que só existe direito onde, em caso de recusa, chegam os "homens com elmos de pontas" forçando as pessoas a executarem os pores teleológicos socialmente necessários" (LUKÁCS, 2011, p. 362).

Nesse, como em quase todos os momentos da fase madura de seu pensamento, percebe-se que Lukács encarava como uma das tarefas mais importantes para a reconstrução de uma perspectiva teórica autenticamente revolucionária a crítica rigorosa das versões mecanicistas do pensamento marxiano. Reconhecia nessas um tipo de distorção grosseira e de desvio com relação à dupla complexidade da cientificidade de Marx: primeiro a de seu objeto e, em segundo lugar, em referência ao seu caráter teórico real. $\mathrm{O}$ que inclui como momento surpreendente a denúncia de que o mecanicismo de certa tradição materialista teria sido vítima da permanência de uma concepção quase religiosa dos liames entre base material econômica e superestrutura ideal/ideológica. Convertendo a base em uma espécie de "Criador" e a superestrutura em "criatura", essa posição teria lido na relação a impossibilidade, ou a pecaminosidade, no fato de que o segundo viesse a superar o primeiro. Contra isso, argumenta que:

Os processos reais do ser, porém, nada têm a ver com uma hierarquia de valores tão simples. Seus processos complicados e irreversíveis produzem 
nexos ontológicos cada vez mais complicados, categorias diferenciadas, embora sem criar relações de valor. Mas é parte integrante das constituições internas do ser social que nele, em certas circunstâncias, transformações do ser também possam produzir relações de valor. (Demonstramos, anteriormente, como em fases bem primordiais esses pores valorativos são resultados inevitáveis, ontologicamente inelimináveis, de todo processo de trabalho.) Mas para o marxismo isso não resulta em uma superioridade, na hierarquia de valores, da base que desencadeia uma reação de transformação em relação ao que foi desencadeado (LUKÁCS, 2011, p. 364).

Objetando contra essa hierarquização simplória de instâncias ônticas, Lukács pretende compreender, intentando fazê-lo a partir de Marx, o modo concreto da relação. Para tanto trata de realudir à distinção, para ele central, dessa valoração para com o tema da prioridade ontológica. Nos quadros de determinação desta última, não se trata de identificar ser e valor, mas de delimitar o nexo entre o ser e suas formas variadas de expressão, entre elas a ideal, indicando inclusive momentos decisivos em que as formas expressivas tomam parte do movimento de determinação objetivo. 0 que abre caminho também para a posição do problema da relação mesma entre cientificidade e efetividade, bem como entre as categorias e o movimento real:

Trata-se exclusivamente do problema mais geral da oposição entre processualidade histórica concreta e universalidade abstrata na determinação concreta das categorias. Já Hegel, em seus primeiros tempos, protestou contra tal determinação de Kant, tipicamente metodológica, segundo a qual do conceito gnosiológico de depósito seguiria, necessariamente, a proibição moral de sonegá-lo. Metodologicamente, a sua crítica - desse modo atingindo também a concepção stalinista - é no sentido de que se subordinem processos sociais práticos heterogêneos como consequências lógicas homogeneizadas de uma determinação abstrata do conceito, perdendo com isso sua real essência, isto é, de serem momentos concretos de um processo histórico concreto e, por isso, de serem também momentos da práxis social expostos à mudança (LUKÁCS, 2011, p. 366).

O que faculta ao filósofo húngaro afastar como improcedente a concepção de talhe stalinista, segundo a qual há que "aplicar" o "materialismo dialético", considerado como vertente e opção epistêmica, à realidade social. Perversão teórica arrimada no procedimento caracterizado pela subordinação de "processos sociais práticos heterogêneos como consequências lógicas homogeneizadas de uma determinação abstrata do conceito" (LUKÁCS, 2011, p. 366), aspecto este de talhe não apenas idealista, mas também, e principalmente, especulativo. O finito se transforma em simples "figura" de uma determinação conceitual considerada como uma entidade substancial e infinita. É importante frisar o quanto este tipo de viés teórico acabou se firmando como imagem dominante do pensamento marxiano, à revelia deste, tanto nos ambientes propriamente acadêmicos de diversas áreas da cientificidade quanto no terreno do senso-comum. 
O que opõe Lukács à tradição de inspiração neokantiana, da qual alguns elementos conceituais e ideológicos podem ser encontrados na tendência da teoria e da prática do capital por ele denunciada como manipuladora, é exatamente a identificação do caráter objetivo como um traço imanente ao real. Não somente as coisas existem independentemente da consciência e da percepção humanas, mas têm também uma dada forma de configuração que lhes é inerente, ainda que esta esteja sempre em mutação, seja como tal uma forma de ser dinâmica. Nesse contexto:

Como ponto de partida, deve servir a constatação de que a objetividade é
uma forma originária, isenta de gênese (por isso inderivável por meio do
pensamento), de todo ser material. Aos olhos de Marx, ser é sinônimo de ser
objetivo. Não existe "outra força", seja espiritual ou material, que teria
imposto, "de fora", uma objetividade a um ser em si informe (caótico), como
pensa a maioria dos seus predecessores, conteudística e formalmente, das
mais variadas maneiras (LUKÁCS, 2011, p. 367).

Nessa direção, a utilização marxiana do termo Kategorie, para o filósofo húngaro, revela como a determinação é entendida de modo totalmente diverso daquele observado na tradição dominante em filosofia. Não é ela nem uma entidade subsistente de natureza imaterial, nem é tão somente uma figura mental, um nome, cuja existência derive unicamente da atividade da subjetividade. Ao contrário:

[...] categoria significa, textualmente, asserção, portanto, a formulação intelectivo-verbal daquilo que é, no mundo existente, o permanente, o essencial, que, devido a essa essencialidade, são suas determinações permanentes e duradouras. Parece, por isso, em geral evidente que aqui o pensamento se aproxima da realidade, imprimindo-lhe essa essencialidade (LUKÁCS, 2011, p. 367).

São momentos gerais do existente em sua finitude irredutível, os elementos determinativos de sua malha categorial, a qual, uma vez perfazendo uma totalidade articulada, é a própria positividade posta em sua independência objetiva e concreta. O que diferencia de maneira clara a propositura marxiana da de Hegel. O que é particularmente decisivo no modo como é entendida a historicidade numa e noutra, por exemplo. Caráter essencial das formas do ser, o histórico apresenta em Marx e em Hegel aspectos distintos e opostos. No autor do Espírito, segundo Lukács, nota-se a presença necessária, dada sua compreensão das categorias como formas lógicas puras e a priori, de uma teleologia que preside o decorrer da efetividade em seus momentos até a consecução de um determinado patamar absoluto de realização da Ideia de liberdade. Para Marx, há o reconhecimento da irreversibilidade dos processos, da causalidade processual, sem que, entretanto, haja a atribuição de uma finalidade inscrita e agindo como princípio movente por meio das ocorrências e transformações históricas concretas. Muito menos ainda a postulação de um ponto final - de cunho 
lógico, portando uma necessidade teleológica - para a história concreta. O tema de um "fim da história" é, tem de ser obrigatoriamente, estranho ao pensamento de Marx, dado seu caráter ontológico materialista e imanentista.

Uma vez que as categorias científicas portam virtualmente esse caráter de expressões da concretude do ser, o conhecimento em Marx, segundo Lukács, tem como uma das suas determinações o fato de ser irremediavelmente post festum. Ainda que seja possível a identificação racional e conceitual de tendências de desenvolvimento do fenômeno, tal operação somente é exequível na medida em que o pensamento se submeta à ordem objetiva do processo examinado. Pois:

[...] tais processos nunca podem realizar quaisquer tendências gerais que não
brotem de sua própria dinâmica. O seu caráter puramente causal, não
predeterminado, distante de qualquer teleologia, mostra-se na constituição
variada, nunca homogeneamente evidente, sempre encerrando movimentos
desiguais, perpassada de acasos, dos processos singulares em sua relação
com o processo em seu conjunto de toda maneira do ser (LUKÁCS, 2011, p.
375).

São tão somente linhas tendenciais que se afiguram como possibilidades objetivas, mais ou menos prováveis, subsumidas ao itinerário efetivo das relações; ou seja, não podem ser tomadas como expressões de um rumo prefigurado de modo teleológico a partir de um princípio de inteligibilidade qualquer. Tendências que precisam ser ulteriormente confirmadas ou não, em alguma medida, para serem admitidas como momentos de uma análise do efetivo e não aceitas como desdobramento apriorístico de um filosofema logicamente encadeado. As leis tendenciais de desenvolvimento histórico de um dado modo de produção da vida humana, igualmente devem ser consideradas a partir dessas mesmas observações. $O$ que evidentemente não abole a complexidade particular à aproximação das formas de existência do ser social. A historicidade específica dessa esfera aparece e precisa ser reconhecida como caráter oriundo da própria atividade real dos homens. Formas de ente/processo efetivo, mas de talhe diverso daquele da naturalidade, mesmo dos biológicos. Resultados, e pressupostos postos, de uma determinada prática objetiva que plasma concretamente as formas naturais em objetos humanos. Historicidade efetiva que nada mais é que um dado aspecto essencial da objetividade movente e movida, como tal "a história é a transformação das categorias" (LUKÁCS, 2011, p. 382), por meio da confrontação real dos homens com a natureza, bem como os modos concretos sob os quais transcorre este processo.

Delimitada como propriamente práxis, essa atividade fundamentalmente 
humana põe determinados aspectos inauditos em relação ao que se verifica no conjunto da natureza: uma característica presença mediadora da consciência. Assim:

\begin{abstract}
Exatamente esse desenvolvimento objetivo do ser social, em que as categorias de tipo sempre mais puramente social atingem o predomínio objetivo nos processos decisivos, nos reconduz para a questão da concepção marxiana da gênese e operatividade social da consciência humana, de sua ligação inseparável com a práxis social como momento mais essencial daqueles processos objetivos a partir de cuja coatuação se estrutura o ser social. Essa relação genética e operativamente inseparável é uma das mais importantes e centrais determinações ontológicas objetivas do ser social. Os complexos tantas vezes concebidos separadamente na filosofia: realidade objetiva e imagem de mundo intelectual são momentos inseparáveis no plano ontológico de um processo, em última análise unitário, de caráter histórico (LUKÁCS, 2011, p. 380).
\end{abstract}

Consciência que não pode ser outra coisa senão o bewusst sein..., ou seja, o estar consciente de..., e não uma figura autônoma de cunho imaterial. Consciência que somente é como tal, e pode ser entendida racionalmente, na práxis e em referência necessária a esta. É então um momento da articulação, existindo como determinação operante em remetimento obrigatório à totalidade das categorias. O que, assinale-se novamente com vigor, possui amplas consequências para a determinação do movimento da cientificidade em relação ao do ser. Porquanto não seja obra de uma subjetividade pairando acima ou existindo em independência da efetividade concretamente material, o esforço de intelecção científica tem necessariamente de ser posto pelas condições sociais de possibilidade objetivamente dadas. A ciência não pode ser concebida em isolamento daquelas condições e do condicionamento delas resultante. Ao contrário, precisa ser apreendida como, um dos tantos, pores do sujeito objetivamente configurado, existindo como processo social individual de ser.

\title{
Referências bibliográficas
}

ALVES, A. J. L. A cientificidade na obra marxiana de maturidade: uma teoria das Daseinsformen. 2012. Tese (Doutorado) apresentada ao Instituto de Filosofia e Ciências Humanas da Unicamp. Campinas, 2012.

KAUTSKY, K. As três fontes do marxismo. São Paulo: Global, [s.d].

LUKÁCS, G. Para uma ontologia do ser social. v. I. São Paulo: Boitempo, 2012.

LUKÁCS, G. Prolegômenos para uma ontologia do ser social. São Paulo: Boitempo, 2011.

LUKÁCS, G. Zur Ontologie des gesellschftlichen Seins. Darmstadt und Neuwied: Hermann Luchterhand Verlag, 1984.

\section{Como citar:}

ALVES, Antônio José Lopes. A cientificidade marxiana nos Prologomena de Lukács. Verinotio, Rio das Ostras, v. 27, n. 1, pp. 401-427, jan./jun 2021. 